\title{
Impacto del COVID-19 en el derecho penal uruguayo. Análisis de la comisión e imputación de los delitos en medio de una pandemia
}

\author{
Dra. Camila Vittori Chollet
}

Universidad de la República

Camila.vittori7@gmail.com

Código ORCID: https://orcid.org/0000-0001-9415-8084

\section{Dra. María José Graziani Martínez ${ }^{* \star}$}

Universidad de la República

mariajosegraziani@outlook.com

Código ORCID: https://orcid.org/0000-0002-7973-2006

\section{Resumen:}

La aparición del COVID-19 ha sacudido al mundo entero desde su aparición, forzando a los Estados a adoptar el compromiso de desarrollar políticas públicas que contribuyan a evitar la expansión del virus, y a mermar los efectos del fuerte impacto que ha provocado. En ese sentido, nos encontramos ante una situación anómala, en donde más allá de los mandatos generales del Derecho Penal, dependiendo del contexto, podría interpretarse que con nuestro accionar, estamos incurriendo en delitos. Dicho esto, surge la interrogante sobre cuáles son los tipos penales a los que nos expone esta restricción de derechos a la que podemos vernos sometidos y cuál es la consecuencia por el incumplimiento de las medidas de prevención. Por otra parte, en estos casos, el bien jurídico tutelado, salud pública, debe ser entendido como un instrumento esencial de legitimación e interpretación del Derecho Penal. Donde hay un interés relevante social, existe la posibilidad que el Estado, a través de políticas criminales y del jus puniendi, establezca conductas que puedan ser reprimidas si esos bienes jurídicos son puestos en peligro. En ese sentido, no cualquier conducta puede ser relevante penalmente, y debemos tener en cuenta diferentes aspectos para ver si esa conducta adquiere la relevancia necesaria para la aplicación del Derecho Penal ante estas circunstancias. A raíz de todo ello, mediante el presente artículo nos

\footnotetext{
* Doctora en Derecho y Ciencias Sociales por la Universidad de la República, Uruguay (UDELAR). Experiencia en Dirección General de Comercio, asesorando en materia de relaciones de consumo y prestando tareas en el área jurídica de dicho organismo, contando además con experiencia en materia de resolución de conflictos a través de audiencias de mediación. Ha participado además en numerosos seminarios relacionados con la materia penal. Es oyente en cátedra de Derecho Penal por la UDELAR. Actualmente ejerce la profesión de manera independiente.

** Doctora en Derecho y Ciencias Sociales por la Universidad de la República, Uruguay (UDELAR). Ha trabajado para la firma Guyer \& Regules en el departamento Corporativo, actualmente brindando sus servicios dentro del área legal en la empresa internacional Deloitte. Posee experiencia asesorando a distintos clientes tanto nacionales como extranjeros en diversos asuntos como en materia penal empresarial. A nivel técnico, actualmente se encuentra cursando una maestría en Derecho Penal Económico en la Universidad de la Rioja, en España. Asimismo, es Investigadora Asociada Grado I en International Center of Economical Penal Studies (ICEPS) y ha escrito y publicado artículos sobre aspectos penales. Es oyente en cátedra de Derecho Penal por la UDELAR.
} 
propusimos introducir al lector en el análisis de las diversas políticas públicas adoptadas hasta el momento en Uruguay a efectos de proteger la salud pública, y su impacto desde la perspectiva del Derecho Penal.

Palabras clave: COVID-19; coronavirus; Derecho Penal; delitos; salud pública

\section{Abstract:}

"Impact of COVID-19 on Uruguayan Criminal Law. Analysis of the commission and imputation of crimes in the midst of a pandemic". The appearance of COVID-19 has affected the most to the whole world since the beginning, forcing States to adopt the commitment to develop public policies that contribute to prevent the spread of the virus, and to diminish the effects of the strong impact it has caused. In this sense, we are facing an anomalous situation, where beyond the general mandates of criminal law, depending on the context, may be interpreted that with our actions we are incurring in crimes. Having said that, the question arises as to which criminal categories this restriction of rights exposes us to and what the consequences are for failure to comply with preventive measures. On the other hand, the legal good protected, public health, shall be understood as an essential instrument of legitimization and interpretation of criminal law. Where there is a relevant social interest, there is the possibility that the State, through criminal policies and jus puniendi, may establish conducts that may be repressed if those legal rights are endangered. In this sense, not just any conduct can be criminally relevant. We must take into account different aspects to see whether that conduct acquires the necessary relevance for the application of criminal law under these circumstances. Considering all this, in this article we set out to introduce the reader to the analysis of the various measures adopted to date in Uruguay for protecting public health, and their impact from the perspective of criminal law.

Keywords: COVID-19; coronavirus; Criminal Law; crimes; public health

Recibido: 13.10 .2020

Aceptado: 04.12.2020 


\section{Introducción}

Hace ya casi 7 meses desde que el COVID-19 (en adelante, "COVID-19" o "coronavirus" indistintamente) irrumpió en Uruguay (marzo, 2020) y llegó para marcar la agenda de nuestro país y del mundo, de una forma totalmente inesperada y rápida, poniendo en jaque a todos los países del mundo. Lo que acabamos de expresar, conlleva: desde cambios rotundos en la economía, arrastrando crisis mundiales y nacionales; fuerte dependencia tecnológica tanto para personas físicas en sus vidas cotidianas, como para el desempeño y la continuidad de las empresas; implementación abrupta y rápidamente difundida del teletrabajo, el distanciamiento social; nuevas formas de implementar, desarrollar y recibir la educación; el desarrollo de procedimientos judiciales; hasta por supuesto, un aspecto que muchos nos planteamos y que es objeto del presente trabajo, la comisión e imputación de los delitos en medio de una pandemia, esto es, el impacto en el Derecho Penal.

Desde la llegada del virus, los Estados han tratado de acoplarse a la nueva situación a través de la imposición de medidas sanitarias en algunos casos sin llegar al confinamiento obligatorio, con el objetivo de lograr salvaguardar el bien jurídico colectivo de la salud pública.

Entiéndase salud pública, no como la integridad física de una persona o de muchas individualmente consideradas, sino, la de todos (Ferreira, Ramírez, 2020), como conjunto, en atención al bienestar general de la colectividad cuya protección en el caso de Uruguay, es conferida al Estado por la propia Constitución de la República en su artículo 44:

"El Estado legislará en todas las cuestiones relacionadas con la salud e higiene públicas, procurando el perfeccionamiento físico, moral y social de todos los habitantes del país.

Todos los habitantes tienen el deber de cuidar su salud, así como el de asistirse en caso de enfermedad. El Estado proporcionará gratuitamente los medios de prevención y de asistencia tan sólo a los indigentes o carentes de recursos suficientes" (Constitución de la República Oriental de Uruguay, 1967).

En este sentido, la salud pública se responde a la necesidad de la sociedad de gozar de las condiciones mínimas de salubridad e higiene que garanticen ciertos estándares de la salud de cada individuo y de la colectividad.

Asimismo, en el artículo previamente citado, se regulan 3 situaciones jurídicas distintas de deber. La primera de ellas es la del Estado como encargado de proteger y garantizar la salud como bien jurídico individual y supraindividual; la segunda es la de los individuos que tienen el deber de asistirse en vías de proteger su propia salud, y la tercera es la de los proveedores de servicios de asistencia, que se encuentran en la obligación de proteger a sus pacientes y usuarios.

Al momento de la aparición del SARS-CoV-2 y su enfermedad COVID-19, ambas eran totalmente desconocidas, pero terminaron provocando una pandemia que hoy en día ha causado más de 33 millones de infectados y más de 1 millón de muertos -siendo prácticamente escasos los países que no han confirmado su aparición al día de hoy-. En consecuencia, a raíz de estas cifras escalofriantes y desde su avasallante expansión, va de suyo el carácter excepcional y de urgencia que han tenido todas las medidas adoptadas en todo el mundo y principalmente en Uruguay, teniendo en 
cuenta que estamos hablando de una situación que no tiene precedentes, y que presenta un margen muy grande de incertidumbre respecto a su evolución.

Tal como se ha expuesto, este virus ha mostrado una extrema rapidez de contagio, y de esa forma se ha cobrado la vida de cientos de miles de personas en el mundo, siendo declarado por la Organización Mundial de la Salud (OMS) como pandemia, decretándose un nivel máximo de alerta internacional. Uruguay por su parte, decretó la emergencia sanitaria a través del Decreto $N^{\circ}$ 093/020 de fecha 13 de marzo de 2020 (en adelante, el "Decreto"). Cuando hablamos de "emergencia sanitaria", nos referimos a una situación extraordinaria que provoca un riesgo para la salud pública, a través de la propagación de la enfermedad de la que hablamos.

\section{El COVID-19 desde la óptica del Derecho Penal}

La misión del Derecho Penal es la de garantizar la tutela de los "bienes jurídicos", es decir, aquellos bienes vitales imprescindibles para la convivencia humana en Sociedad y para cada ser humano de forma individual, que, por lo tanto, resultan merecedores de protección mediante el empleo del poder coactivo del Estado.

A efectos de garantizar la tutela, el Estado es quien debe fijar el objetivo a proteger, determinando el bien jurídico que merece protección. Si bien estamos de acuerdo en que las medidas adoptadas en épocas de pandemia son aspectos claves a la hora de prevenir y confrontar los efectos del virus, es evidente que se requiere la atención de las autoridades en su desarrollo e implementación de medidas en atención a distintos niveles. Con lo cual, una vez más, surge la duda de si es precisamente el Derecho Penal el encargado de acudir este problema.

En ese sentido, debe tenerse siempre presente el carácter de ultima ratio del Derecho Penal, el cual se constituye como un último escudo defensivo del Estado tendiente a proteger un mínimo ético exigible por todas las personas. En ese sentido, Silva Sánchez sostiene lo siguiente:

"la visión del Derecho penal como único instrumento eficaz de pedagogía político-social, como mecanismo de socialización, de civilización supone una expansión ad absurdum de la otrora ultima ratio. Pero sobre todo porque, además, tal expansión es inútil en buena medida, porque somete al Derecho penal a cargas que éste no puede soportar" (Silva Sánchez, 2001, p. 65)"

Agrega, además, que "se trata de desviar al Derecho penal las grandes cuestiones del funcionamiento de la comunidad como tal, cuestiones que hoy por hoy ni las instituciones políticas ni los grupos sociales son capaces de resolver" (Silva Sánchez, 2001, pp. 65-66).

Ahora bien, es de interés conocer las medidas adoptadas por el Poder Ejecutivo en contexto de pandemia y analizarlas desde el punto de vista de su cumplimiento. Lo antedicho supone necesariamente un enfoque que involucra aspectos de Derecho Penal, todo lo cual sin dudas ha impactado y seguirá impactando tanto en personas jurídicas, como en personas físicas.

A continuación, adentraremos en el tema de las consecuencias en cuanto al incumplimiento de las medidas impuestas por el Estado en el contexto de la emergencia sanitaria, así como la comisión e imputación de los posibles delitos según nuestro Código Penal, para, luego, contar con las herramientas necesarias a los 
efectos de responder la siguiente consulta: ¿es el Derecho Penal la herramienta más adecuada para solucionar este tipo de cuestiones, considerando su carácter de "última ratio"? Y en la misma línea, ¿existe otro medio menos lesivo para proteger el bien jurídico que se pretende?

\subsection{Bien jurídico "Salud Pública"}

La salud pública es un bien jurídicamente protegido de jerarquía supralegal, cuyo goce se encuentra garantizado por los artículos 7 y 72 de la Constitución de la República.

Nuestro Código Penal, en su Libro II, Título VII, dispone entre los delitos contra la Salud Pública la fabricación de sustancias alimenticias o terapéuticas, el ofrecimiento comercial o venta de sustancias peligrosas para la salud, falsificadas, adulteradas o desnaturalizadas, el envenenamiento o adulteración culpables de las aguas destinadas a la alimentación la expedición sin receta médica o menoscabo de sus prescripciones y el daño por violación de las disposiciones sanitarias. Este último, será objeto de análisis en el capítulo 2.3.2 del presente artículo.

Según la Constitución de la Organización Mundial de la Salud, “....salud es un estado de completo bienestar físico, mental y social, y no solamente la ausencia de afecciones o enfermedades" (Organización Mundial de la Salud [OMS], 2006). En nuestro país, la salud pública, como bien jurídico protegido, se configura como un conjunto de condiciones positivas y negativas que posibilitan el bienestar general de la colectividad, garantizando unas condiciones mínimas de salubridad e higiene, obedeciendo, así, al mandato constitucional previsto en el artículo 44. En virtud de lo antedicho, la salud pública alcanza un nivel autónomo de protección penal y constituye un bien jurídico colectivo e independiente de la salud propia e individual de cada persona.

La protección penal de este bien jurídico, queda entonces reservada en este ámbito para las infracciones más graves o lesivas contra la salud pública, por el principio de la mínima intervención frente a otras ramas del ordenamiento.

Tal como decía Carrara:

"Los delitos contra la salud pública serán, pues, todos los actos por medios de los cuales ciertas sustancias que sirven para la nutrición, para el mantenimiento de la vida de un grupo de hombres y en general para sus necesidades cotidianas, llegan a corromperse, a infectarse, a convertirse en cambio en causa de enfermedades de daños para la salud y aun de muerte para un número indefinido de ciudadanos, y posiblemente de todos. Es innegable que todos los habitantes de una ciudad tienen igual derecho a que no se inficione el aire que los circunda, y el que viola este derecho no ofende a un solo individuo o a una sola familia determinada, sino que ofende directamente a todos los asociados, pues viola un derecho común a todos; y dígase lo mismo del agua y de cualquier otra cosa que puede hacer accesible al uso de todos" (Carrara, 1998, pp. 262-263).

\subsection{Análisis del Decreto № $093 / 2020$ - Declaración de emergencia nacional sanitaria}


Enunciaremos a continuación algunas de las medidas impuestas por el Decreto antes mencionado a raíz de la emergencia sanitaria:

1. Suspensión de espectáculos públicos hasta que el Poder Ejecutivo lo determine.

2. Cierre preventivo y provisorio de los centros turísticos termales, públicos y privados ${ }^{1}$.

3. El asilamiento por un período de catorce días para aquellas personas que: i) sean portadores del virus; ii) presenten fiebre, tos o síntomas respiratorios y que en los últimos quince días se hayan encontrado en zonas de alto riesgo ${ }^{2}$; iii) quienes hayan estado en contacto directo con personas portadoras de COVID-19; iv) las personas que ingresen al territorio nacional que se hayan encontrado o transitado zonas de alto riesgo.

Las medidas sanitarias adoptadas no presentan mayores dificultades de entendimiento, puesto que el propio Decreto, define las expresiones "contacto directo", "zonas de alto riesgo" y "permanecer aislado".

Como toda norma que dispone el acatamiento de una conducta, se establece luego la consecuencia ante su incumplimiento. Es así que el artículo 11 del Decreto dispone que:

"en caso de verificarse incumplimiento de lo dispuesto en los artículos 8 y 10 del presente Decreto, el personal de salud o quien tome conocimiento de lo sucedido, deberá comunicarlo de inmediato a la Dirección General de la Salud del Ministerio de Salud Pública, que de entenderlo pertinente dará noticia a su División Servicios Jurídicos a efectos de realizar la denuncia penal correspondiente" (Decreto Nº93/020, 2020).

En ese sentido, al día de hoy, nos hemos informado sobre el registro de un gran número de denuncias penales derivadas del incumplimiento de tales medidas sanitarias.

A consecuencia de estas medidas, cada vez que los ciudadanos uruguayos se plantean la posibilidad de incumplir las mismas o se alertan ante la violación de una de ellas por un tercero. La primera interrogante que se plantean es si directamente pueden tener consecuencias penales, por ser estas las más "amenazantes" para cualquier sujeto, ya que, en una primera lectura, lo asimilan con la privación de libertad y pueden ver reprimida la acción de incumplimiento.

Ahora bien, sin pronunciarnos aún a favor o en contra de optar por las herramientas que se derivan del Derecho Penal como solución a esta cuestión y al cumplimiento de las obligaciones impuestas por el Decreto, analizaremos cuál es la respuesta del Derecho Penal uruguayo, para luego recién concluir si su aplicación es efectiva o no.

\subsection{Respuesta del Derecho Penal frente a la situación de emergencia sanitaria}

Hay que extremar el análisis de las conductas para que, además de encajar en el tipo penal formalmente, tengan un contenido material susceptible de habilitar la respuesta punitiva estatal. Esto exige, una adecuada delimitación del ámbito que debe ocupar el Derecho Penal en los delitos que vamos a analizar. 
Nuestro Código Penal prevé 4 figuras delictivas que merecen ser destacadas y estudiadas en este contexto de emergencia sanitaria: a) delito de Desacato b) delito de Daño por violación de las disposiciones sanitarias c) delio de Lesiones y d) delito de Homicidio culposo.

\subsubsection{Delito de Desacato}

En primer lugar, el delito de desacato se encuentra regulado en el artículo 173 de nuestro Código Penal y la acción penalmente sancionada en él consiste en resistir o desobedecer el mandato de la autoridad. Cierta parte de la doctrina afirma que en este artículo se encuentran contempladas las personas que se encuentren dentro de la situación del artículo 8 del Decreto y que incumplan las medidas de aislamiento. Este delito es castigado con una pena de tres a dieciocho meses de prisión.

Respecto de esta figura penal, el Doctor Germán Aller (Abogado penalista y director del Instituto Uruguayo de Derecho Penal y Criminología de la Universidad de la República - UDELAR) explicó en ocasión de una entrevista realizada por el Diario El País que:

"el delito de desacato hay que analizarlo con cierto cuidado. Tiene que implicar o una ofensa o una desobediencia abierta al funcionario. No es meramente la ley en forma aislada, porque si no cometería delito de desacato toda persona que no pague tributos. Aquel que no pague tributos dolosamente comete el delito de defraudación tributaria, pero no el de desacato. Lo mismo con el hurto o rapiña, no se configura el desacato por incumplir la ley". Seguidamente remarcó en la entrevista "requeriría una desobediencia abierta al funcionario público, y no a la ley." (Aller, 2020)

Siguiendo la línea de pensamiento -la cual personalmente acompañamos- en el marco de la emergencia sanitaria, entendemos que no cometería delito de desacato quien sale de su casa en medio de una cuarentena obligatoria, sino que, para configurar la conducta típica regulada en el artículo 173 del Código Penal, debería desobedecerse una orden directa del funcionario público, ya que entendemos que no basta simplemente con la mera desobediencia a la ley. En el ejemplo planteado, se requeriría, entonces, que el funcionario solicite a la persona que sale de su casa que regrese a ella y la persona se resistiera a hacerlo.

En ese sentido, se han conocido varios dictámenes fiscales a través de los cuales se imputa debidamente el desacato de personas portadoras de COVID-19 que incumplen el aislamiento o las medidas que se le disponen, poniendo en peligro la expansión del virus e incurriendo en el delito de desacato analizado precedentemente.

A modo de ejemplo y para que pueda observarse su puntual aplicación, la Fiscalía Letrada Departamental de Rivera de $3^{\circ}$ turno imputó a una persona portadora de COVID-19 por reiterados delitos de desacato, uno de ellos en concurso formal con un delito de violencia privada en calidad de autor ${ }^{3}$.

En consecuencia, y según el ejemplo planteado en donde una persona que se encuentra obligada a hacer la cuarentena, no cumple con dicho precepto, y al incumplir el confinamiento provoca un daño, la figura delictiva que podría aplicarse, es la prevista en el artículo 224 del Código Penal, la cual analizaremos a continuación. 


\subsubsection{Delito de Daño por violación de las disposiciones sanitarias.}

En segundo lugar, el delito de Daño por violación de las disposiciones sanitarias se encuentra regulado en el artículo 224 del Código Penal y su principal fin es proteger el bien jurídico colectivo de la salud pública en los términos analizados en el capítulo 2.1. del presente. Cuando hablamos de "daño" nos referimos a la lesión o menoscabo de un interés. En el caso que analizamos, la lesión se produce sobre el goce del bien jurídico, salud pública, siendo el daño más grave que puede producirse, en este sentido, la muerte, que analizaremos más adelante.

Este delito sienta sus raíces con la sanción del Código Penal de 1934; no obstante, en ese entonces era una figura de peligro abstracto, la cual se consumaba con la mera desobediencia "de las disposiciones sanitarias dictadas por la autoridad en casos de epidemia" (Código Penal de la República Oriental de Uruguay, 1980). De forma posterior, la situación epidémica a raíz del brote de aftosa a comienzos del año 2000 provocó que, a través del artículo 64 de la Ley № 17.292, se modificara su redacción hasta entonces vigente, introduciendo un tipo penal aparentemente de daño (Ferreira, Ramírez, 2020).

Ahora bien, se preguntarán qué implica esto. Implica, pues que, los delitos de peligro se vean consumados con la simple puesta en "peligro para un bien protegido por la ley penal" (Ferreira, Ramírez, 2020). Mientras que los delitos de daño se consuman con la lesión efectiva del bien jurídico, es decir, ambos delitos de configuran cuando tenemos una acción típica, antijurídica y culpable, siendo ambos delitos de resultado, con la diferencia de que en los delitos de peligro se adelanta la consumación respecto de los delitos de daño.

Sin embargo, la redacción del artículo fue nuevamente modificada por la que actualmente se encuentra vigente, estableciendo una solución de difícil aplicación, en tanto, según el texto, el daño a raíz de la violación de las disposiciones sanitarias debe producirse efectivamente, es decir, de manera tangible.

Por ello, resulta lógico afirmar que el referido artículo 224 ha presentado fuertes dificultades en su aplicación, y esas dificultades ha intentado ser subsanadas 0 completadas, a nuestro criterio, con los diversos decretos posteriores a la declaración de situación de emergencia sanitaria en nuestro país, a fin de contar con una herramienta segura y efectiva que respalde el cumplimiento de las disposiciones sanitarias.

Precisamente es por esta dificultad que exponemos que se ofrece el artículo 224 del Código Penal. El día 23 de marzo de 2020 se presentó en la Cámara de Representantes (CRR), un Proyecto de Ley (en adelante, el "Proyecto"). El Proyecto fue aprobado por la CRR el pasado 1 de setiembre y, al día siguiente (2 de setiembre), tuvo paso a la Cámara de Senadores (CSS). En el marco de la situación de emergencia sanitaria, el objetivo de este Proyecto es modificar el texto del artículo en análisis, ya que, en su exposición de motivos, dispone que "las actuales circunstancias sanitarias del país obligan a reflexionar acerca de las herramientas que nuestro ordenamiento jurídico confiere a los poderes de gobierno para ejercer las funciones que le son constitucionalmente encomendadas" (Código Penal de la República Oriental de Uruguay, Artículo 224, 1994). La modificación de este artículo fue también sugerida por el Fiscal de Corte, Jorge Díaz, quien aconsejó la adaptación de este tipo penal como respuesta a las dificultades prácticas que estaban teniendo las fiscalías para aplicar el delito de desacato -tal como se describe en el capítulo precedente - 
Con lo anterior, el principal argumento del Proyecto radica en que los legisladores no le encuentren sentido a esperar a que la violación a la disposición sanitaria cause un daño efectivo para considerar que la conducta del agente es suficientemente peligrosa y, así, merecer la represión penal. Asimismo, esta nueva redacción que se intenta, con algunas variantes menores, resulta similar a la redacción original del artículo dada por la Ley № 9.155 (Ferreira, Ramírez, 2020) -recordemos que este cambio está pensado en su mayoría, en contexto de pandemia y, en efecto, con la intención de que su aplicación sirva como mecanismo previsor de su expansión-.

Ahora bien, la redacción actual del referido artículo 224, castiga al que "mediante violación de las disposiciones sanitarias dictadas y publicadas por la autoridad competente para impedir la introducción o la propagación en el territorio nacional de enfermedades epidémicas o contagiosas de cualquier naturaleza, causare daño a la salud humana o animal...". Como puede observarse, esta redacción nos coloca frente a un delito de daño, es decir, que la norma penal requiere la efectiva causación de un daño a la salud humana o animal a través de la violación de disposiciones sanitarias, lo que supone que se castigará la causación efectiva del daño, la cual es precisa y puede observarse. En consecuencia, la sola violación a una disposición sanitaria sin que produzca perjuicio alguno no es suficiente para que la conducta sea sancionada penalmente por este tipo penal (Ferreira, Ramírez, 2020).

Dicho esto, pasaremos a exponer lo que el Proyecto de Ley pretendía modificar, esto es, el elemento que mencionamos en el párrafo anterior, traducida en la efectiva causación de un daño. El objetivo principal de esta modificación, era entonces convertir el delito tipificado en el artículo 224 del Código Penal, en un delito de peligro, nuevamente. Si el tipo penal se convirtiera en un delito de peligro, se castigaría a quien realizara la acción allí consignada (puesta en peligro) siendo suficiente para el reproche, la provocación del peligro de que ese daño o lesión aparezca. Esto trae consigo la imposibilidad de castigar la conducta en grado de tentativa.

Por otro lado, es preciso discriminar dentro de los delitos de peligro, entre el tipo abstracto y el concreto. En los delitos de peligro abstracto, tal como hemos adelantado, es suficiente con la comprobación de la acción. En este tipo de delitos, el peligro se juzga por el legislador en forma previa a la comisión del delito -a modo de ejemplo, el delito de abandono de niños y de personas incapaces-. Este tipo de delitos cumple el mandato constitucional estableciendo medidas preventivas que adelantan la barrera de protección a los efectos de precaver los riesgos eventuales que pueda sufrir el bien jurídico tutelado, con lo cual no se espera a que se produzca un resultado lesivo ni peligro efectivo. En los delitos de peligro concreto, sin embargo, para realizar el reproche penal de la conducta se requiere que se configure un peligro real de vulneración al bien jurídico protegido; es decir, el peligro se juzga de manera posterior a la comisión del delito y debe producirse efectivamente -a modo de ejemplo, el delito de incendio-.

Precisamente el texto del Proyecto de Ley presentado el día 25 de marzo del corriente era el siguiente:

"El que violare disposiciones vigentes para impedir la introducción al país o propagación de una enfermedad epidémica o contagiosa, será castigado con tres a veinticuatro meses de prisión. Será circunstancia agravante especial de 
este delito si del hecho resultare un grave perjuicio a la economía nacional"4 (Proyecto de Ley, 2020).

Con este texto, según se expresó en la exposición de motivos, se pretendía retornar a la redacción original del artículo según la redacción dada por la Ley $\mathrm{N}^{\circ}$ 9.155. Este proyecto no fue acompañado por algunos legisladores, porque según han expresado, no se contemplaba en él la situación particular de cada sujeto, es decir, si puede o no hacer cuarentena, si tiene o no un domicilio, etcétera. Nuestra opinión al respecto acompaña este último argumento. No creemos que sea necesaria una modificación del artículo 224, puesto que nuestro país ha tomado el compromiso de acatar el confinamiento voluntario en gran medida, y habiendo tenido tanto éxito la concientización con otras herramientas, no resulta necesaria esta modificación.

Habiendo continuado con el curso del trámite parlamentario, se cambió la redacción del Proyecto, proponiéndose la siguiente:

“...el que mediante violación de disposiciones sanitarias dictadas y publicadas por la autoridad competente para evitar la introducción al país o la propagación en su territorio de una enfermedad epidémica o contagiosa de cualquier naturaleza, pusiere en peligro efectivo la salud humana o animal, será castigado con tres a veinticuatro meses de precios. La aplicación del máximo de la pena referida estará especialmente justificada cuando la violación de las disposiciones se produjere durante la vigencia de un estado de emergencia sanitaria declarado por las autoridades competentes."

Con esta última modificación del proyecto, se observa que la intención es convertir a la conducta tipificada en el artículo 224 del Código Penal, en un delito de peligro concreto.

Asimismo, puede observarse que, en la primera redacción propuesta, se suprimía la referencia que se encuentra en el artículo a la "autoridad competente". De esta forma, resultaban mayores "las posibles disposiciones que podrían completar el tipo penal" (Ferreira, Ramírez, 2020) en caso de disposiciones que no sean dictadas precisamente por autoridades competentes desde el punto de vista constitucional a estos efectos. Claramente esto llamó la atención de los operadores del Derecho Penal, quienes sugirieron críticas de inmediato. A raíz de ello, se buscó subsanar el error y se introdujo, finalmente, al segundo párrafo del artículo, de manera que queda de esta forma y deviene en una solución más integral y objetiva.

\section{Como sostienen los autores Ferreira y Ramírez:}

"Por su parte, la segunda supresión que se pretende, a través de la modificación del artículo 224, tiene como principal diferencia sustancial que, en la nueva redacción, se elimina la exigencia de la constatación de un daño efectivo a efectos de que la conducta de "violar las disposiciones sanitarias" puede ser sancionada penalmente" (Ferreira, Ramírez, 2020).

Asimismo, recalcamos que entendemos que la evolución en la redacción del texto del Proyecto refleja la intención de dejar de lado la proposición de un delito de peligro abstracto, transformando la proposición de la disposición a un delito de peligro concreto. 
Ahora bien, independientemente de esta discusión, el artículo 224 puede entenderse como un tipo penal en blanco. La Ley penal en blanco es aquella cuyo precepto es indeterminado en cuanto a su contenido y es fijada con precisión sólo la sanción. El precepto debe ser llenado por otra disposición legal o por decretos o reglamentos (Soler, 1956, p. 133).

Afirman Ferreira y Ramírez:

"Este Decreto, así como los siguientes dictados hasta ahora en igual sentido, completan el tipo penal en blanco previsto en el art. 224, que, en su redacción actual, castiga aquellas conductas que, violando las disposiciones sanitarias dictadas y publicadas por la autoridad competente para impedir la introducción o propagación en el territorio nacional de enfermedades epidémicas o contagiosas de cualquier naturaleza, causen un daño a la salud humana o animal. Es justamente la dificultad que crea la prueba del daño a la hora de aplicar en la práctica la norma en cuestión la base del fundamento de quienes propugnan por la modificación de dicha norma". (Ferreira, Ramírez, 2020).

Ahora bien, cuando hablamos de ley penal en blanco, y, sobre todo, de Derecho Penal, no podemos perder de vista jamás el principio de legalidad. Este principio, podría decirse, es el rector y más importante en la estructura de las normas penales. La tan conocida frase latina "nullum crimen, nulla poena sine praevia lege" establece que solo la ley, y nada más que la ley, puede determinar cuáles son los delitos y las penas en nuestro ordenamiento jurídico. Por lo que, en consecuencia, hay quienes se cuestionan la constitucionalidad de tipos penales como el del artículo 224 por remitir su precepto a otra disposición o reglamento. En ese sentido, el legislador (Poder Legislativo) dicta una ley penal, pero no refiere a la prohibición, sino que hace referencia a que será castigado con tal pena en lo que una ley o un decreto 0 reglamento dictará en un futuro, como es el Decreto en cuestión -elaborado por el Poder Ejecutivo-.

Por los motivos anteriormente expuestos es que las leyes penales en blanco, en nuestro país, son consideradas, por casi la unanimidad de nuestra doctrina, inconstitucionales.

Por otra parte, según el Prof. Milton Cairoli (2000), las leyes penales en blanco sólo pueden integrarse por normas jurídicas creadas y contenidas en una ley en sentido estricto y no por disposiciones que estén jerárquicamente por debajo de la misma.

En ese sentido, y tal como destaca el Dr. Gustavo Bordes (2016), en las aulas de la Facultad de Derecho, enseñan a los alumnos que los principios deben regir en el derecho penal y cuáles son los límites al jus puniendi, pero luego en la práctica, vemos también desde hace mucho tiempo, que lo político prima sobre lo jurídico, como en estos casos.

\subsubsection{Delito de lesiones y homicidio culposo}

Por último, encontramos el delito de Lesiones y el delito de Homicidio culposo (identificados con letras $\mathrm{c}$ y d). De acuerdo con lo que venimos exponiendo, algunas figuras delictivas intentan proteger el bien jurídico supraindividual de la salud pública, y otras, en cambio, apuntan a prohibir conductas que pueden lesionar bienes jurídicos 
individuales como la vida o integridad física de una persona-como es el caso de los delitos anteriormente mencionados-. Respecto a los delitos de Lesiones y el delito de Homicidio culposo, entendemos que la imputación de tales delitos, en el contexto de emergencia sanitaria, no es tarea sencilla.

Ello por cuanto, una vez acreditado el fallecimiento de una persona a causa del COVID-19, habrá que demostrar que aquello se debió al incumplimiento del deber objetivo de cuidado de otro sujeto, que produjo la contracción del virus al fallecido. Ahora bien, a la vez que resulta muy difícil determinar esa relación de causalidad, habrá que prestar mucha más atención al respeto por el principio de inocencia que subyace. Cuando fuera materialmente imposible una prueba contundente de esa relación de causalidad, se habrá que determinar ciertos indicios que nos permitan llegar a la conclusión de que efectivamente existe ese nexo causal.

El delito de Lesiones se encuentra regulado en los artículos 316 a 318 del Código Penal, a lo que el inciso final del artículo 316 dispone: "Es lesión personal cualquier trastorno fisiológico del cual se derive una enfermedad del cuerpo o de la mente" (Código Penal de la República Oriental de Uruguay, Artículo 316, 1994). El delito de Homicidio culposo se encuentra regulado en el artículo 314, y entiéndase como tal, "el que diere muerte a una persona" de acuerdo a lo dispuesto en el artículo 310 del Código Penal (1994). Se trata de dos figuras penales que pueden ser cometidas especialmente en este tipo de contexto.

Teniendo en mente lo anterior, plantearemos un ejemplo: del accionar de un sujeto portador de COVID-19 resulta un daño de lesión o muerte a causa de la trasmisión de la enfermedad a otro sujeto de forma no intencional. Para el reproche penal de la conducta en el caso, será esencial el análisis y la determinación del nexo causal entre la acción del sujeto y el resultado de lesión o muerte, lo que sin dudas presenta dificultades en materia de prueba. El nexo causal puede definirse como la relación causa-efecto que permite establecer cuáles son los hechos susceptibles de causar el daño específicamente, y cuál de ellos fue el que finalmente ocasionó el perjuicio tangible.

\subsection{Conclusión}

Recalcamos que en nuestro país ha tenido un gran éxito la campaña de concientización que se viene realizando desde el mes de marzo del corriente, es decir, desde la aparición del virus COVID-19 en Uruguay, incluso llegándose a que numerosas empresas se adhieran a la misma incluso en contra de sus propios intereses, como ha sucedido con el sector turismo, entre otros.

En este sentido, nos atrevemos a afirmar que existe otro medio menos lesivo para el ofensor que el que ofrece el Derecho Penal para resolver estas cuestiones derivadas de la emergencia sanitaria. Habiendo dicho esto, se ha respondido casi sola la pregunta que planteamos antes sobre si el Derecho Penal era la herramienta más adecuada en estos casos.

Acompañando este pensamiento, podemos citar a Roxin:

"Un Estado de Derecho debe proteger al individuo no sólo mediante el Derecho Penal, sino también del Derecho Penal. Es decir, que el ordenamiento jurídico no sólo ha de disponer de métodos y medios adecuados para la prevención del delito, sino que también hade imponer límites al empleo de la 
potestad punitiva, para que el ciudadano no quede desprotegido y a merced de una intervención arbitraria o excesiva del “Estado Leviatán”' (Roxin, 1997, p. 135).

Surge de lo que hemos expuesto que, desde el punto de vista del Derecho Penal, no contamos con un marco jurídico de adecuada aplicación para la situación sanitaria que está atravesando nuestro país, por lo que, en consecuencia, no resulta pertinente la modificación que se pretende del artículo 224 del Código Penal, como tampoco resulta adecuado recurrir al Derecho Penal, derecho de ultima ratio, como solución a la problemática existente (Ferreira, Ramírez, 2020).

Sin perjuicio de lo antedicho, no podemos dejar de reconocer que, en la población en general, siempre ha predominado el pensamiento de que la herramienta penal es o debe ser la más efectiva frente a todos los problemas y que las penas deben aumentar para lograr la "máxima justicia". Sin embargo, creemos que, de esta forma, dejando todo en manos de un sistema que es de última ratio -o, al menos, debería serlo-, el mismo podría verse colapsado y no cumpliría el fin para el cual fue creado, por lo que entendemos importante siempre considerar herramientas alternativas.

Asimismo, la mayor parte de la doctrina ha coincidido en expresar que el fin del Derecho Penal es la protección de bienes jurídicos, entendiendo por tales aquellos bienes que resultan imprescindibles para la convivencia humana en sociedad. Esa importancia determina que esos bienes sean merecedores de protección por parte del poder coactivo del Estado. En otras palabras, el Derecho Penal no crea bienes, sino que los reconoce, ponderando su importancia en virtud del principio de lesividad (Fleitas, 2015).

Entendemos, entonces, que el Derecho Penal debería quedar reservado para aquellos casos en los cuales el bien jurídico tutelado solo pueda ser protegido y evitado su vulneración por el Derecho Penal, es decir, cuando no existan otros medios menos lesivos para lograr la protección del bien jurídico que se pretende. En otras palabras, cuando el castigo resulte inevitable e imprescindible. Este no resulta ser el caso, puesto que se ha logrado con éxito el confinamiento voluntario con la sola herramienta de la concientización, y ello encuentra su prueba en el éxito del país en el número de contagios, a lo que se debería tener presente, también, el gran nivel de acatamiento que las medidas impuestas han tenido en la población uruguaya y su contribución, en este sentido, al éxito en el número de contagios.

En definitiva, el Derecho Penal, a nuestro juicio, no constituye el mecanismo adecuado para una gestión razonable de los problemas sociopolíticos, ya que el incumplimiento de dichas medidas, puede ser reprimida eficazmente con penas pecuniarias, sin sustituirse con sanciones privativas de libertad.

Por último, cabe destacar que numerosos sectores de la economía se han pronunciado a favor de las medidas e incluso se han sumado a la concientización de la prevención de contagio aún en contra de sus propios intereses, como ocurrió con el sector turismo. Se puede concluir, en este sentido y sin vacilaciones, que los uruguayos han tomado un gran compromiso en la materia, y entendemos que eso ha contribuido al éxito del país en cuanto al bajo número de contagios en relación al resto de los países de Latinoamérica. 


\section{El COVID-19 y la incidencia en el aumento o disminución en la comisión de determinados delitos}

El Pacto (Europa Latinoamérica Programa de Asistencia contra el Crimen Transnacional Organizado) es un programa financiado por la Comisión Europea que busca reforzar las capacidades de las instituciones latinoamericanas en materia de crimen transnacional organizado. En el marco de la pandemia, en marzo del corriente, elaboró un informe sobre la afectación de la pandemia COVID-19 al crimen organizado, advirtiendo la posibilidad del incremento de determinados tipos de delitos, como el cibercrimen o delitos cibernéticos -particularmente a través de estafas en línea y de aplicaciones maliciosas-. Asimismo, han resaltado la probabilidad en el incremento en el lavado de activos, la corrupción o los fraudes y las estafas, tratándose, en su gran mayoría, de delitos económicos. Se trata de delitos que no pueden analizarse de forma aislada y desvinculada de los factores que explican su causa y forma de aparición.

Por otra parte, respecto de los delitos contra las personas, también establece que pueden incrementarse los delitos de odio y los distintos tipos de tráfico como el de drogas, medicamentos, productos sanitarios y complementos alimenticios. Sin perjuicio de lo cual, no obstante, destaca la evidencia sobre ciertos delitos que han disminuido debido al confinamiento, las restricciones de movilidad y el distanciamiento social. Se trata en general de delitos contra la propiedad, tales como los robos con fuerza, violencia o intimidación o la sustracción de bienes del patrimonio histórico y artístico.

\subsection{Delitos informáticos}

En el mundo -y especialmente en nuestro país- en estos últimos meses, se han incrementado considerablemente las denuncias por este tipo de ataques, que encuentran un terreno fértil proporcionado por la situación de emergencia sanitaria que atravesamos. Un ejemplo claro lo constituye el secuestro de datos en mano de los hackers, en donde los delincuentes piden dinero a cambio de liberar la información.

Asimismo, a la vez que se incrementaron las denuncias por este tipo de delitos informáticos, puede afirmarse que otros tantos delitos se han visto disminuidos debido al contexto de confinamiento, especialmente los delitos contra la propiedad.

Es importante destacar que este tipo de delitos - los informáticos- presentan una serie de dificultades para la persecución policial y penal en tanto la investigación requiere conocimientos y procedimientos especiales y técnicos. Además, es importante destacar que la mayoría de estos ataques son realizados desde el anonimato del sujeto activo del delito, ya que habitualmente se utilizan sistemas informáticos de un tercero que ni siquiera se encuentra en conocimiento de que se está usando su red.

Ahora bien, en lo que concierne a los aspectos jurídicos, a diferencia de lo que sucede en otros países, en el sistema jurídico uruguayo no existe un tipo penal específico que tipifique de forma autónoma los delitos informáticos. Sin perjuicio de ello, es común que se denominen "delitos informáticos" a aquellas conductas delictuales que son penadas por un tipo penal autónomo -por ejemplo: estafa, hurto, apropiación indebida, entre otros- y que son efectivizadas a través o mediante la ayuda de medios informáticos. 
Las víctimas de este tipo de ataques pueden denunciarlo ante la Fiscalía competente o ante el Ministerio del Interior. Una vez que una conducta de este tipo es puesta en conocimiento de la Fiscalía competente, cooperan con la investigación la Dirección General de Lucha Contra el Crimen Organizado (DGLCCO) e INTERPOL a través del Departamento de expertos en la materia de Delitos tecnológicos de la Jefatura de Policía de Montevideo.

Hoy en día, son varias las maniobras que se conocen como delitos informáticos, siendo algunos de ellos los siguientes: ciberataques, spam financiero, phishing, pharming, clonación de tarjetas de crédito y débito, compras fraudulentas, robo de contraseñas, delitos telefónicos, fraude de cheques, ofertas falsas de trabajo, falsificación de documentos electrónicos, suplantación de identidad, hackeo, estafas electrónicas, etcétera.

En este sentido, la tecnología posee aspectos positivos y negativos, los cuales han quedado en evidencia en la situación de contexto de pandemia actual que nos encontramos atravesando. Por una parte ha ayudado a muchas empresas y empleados a continuar con su actividad, manteniendo así fuentes laborales -muchos a través del "teletrabajo"-; también ha servido para la mayor propagación de la información que es tan imprescindible para prevenir la propagación del virus, y, por otra parte, esto ha servido como oportunidad para que muchos "hackers" o "piratas de la informática" aprovechen la ocasión para hacerse con documentos y/o información valiosa y confidencial de muchas empresas.

En consecuencia, sobre todo las empresas, debido a la magnitud de sus bases de datos, sistemas electrónicos y redes, deberán tener presente este aspecto y trabajar en la prevención de este tipo de actos que ponen en peligro la confidencialidad, integridad y disponibilidad de los sistemas, redes y datos y su uso abusivo, así como la protección de los intereses legítimos en la utilización y desarrollo de tecnologías de información.

\section{Otras medidas adoptadas por el Gobierno en el contexto de emergencia sanitaria}

No puede negarse que el Uruguay reaccionó a la pandemia de manera muy temprana y desarrolló políticas públicas principalmente enfocadas a la población más vulnerable, a pesar del alto grado de incertidumbre respecto a la evolución en la cantidad de contagios.

Dentro de las medidas adoptadas por el Gobierno a los efectos de reducir el número de contagios, se encuentran algunas destinadas a disminuir el flujo de ingreso de nacionales y residentes argentinos a nuestro país.

Por otro lado, la pandemia sin dudas trajo aparejada una interrupción de la producción del país, repercutiendo esta circunstancia en las empresas, que se han visto forzadas a cerrar o reducir su personal, quebrantando su economía. Si bien esta circunstancia no tiene el mismo impacto en todas las empresas, puede afirmarse que todas ellas se han visto afectadas en mayor o menor medida. La cruel consecuencia de este panorama es el desempleo. Miles de trabajadores se han amparado en seguro de enfermedad y otros tantos han sido enviados al seguro de paro; otros han sido directamente despedidos, y otros se han visto forzados a aceptar importantes reducciones en sus salarios. Ante esta situación, se estableció la flexibilización del seguro de paro. 
Otra medida implementada la constituye la Resolución №055/2020 del Ministerio de Trabajo y Seguridad Social del 20 de marzo de 2020, que establece la autorización de carácter excepcional de la licencia generada en el año 2020, siempre que el mismo sea acordado entre el trabajador y el empleador y tenga su causa en la emergencia sanitaria.

El gobierno uruguayo, como tantos otros, ha tenido la responsabilidad de tomar medidas que propendan al bienestar de los uruguayos, tratando de mermar en el mayor grado posible las consecuencias socio-económicas de la pandemia. Por otro lado, si bien la mayoría de estas medidas en principio fueron establecidas con un plazo aproximado de tres meses aproximadamente, se ha prorrogado sus vencimientos en atención al grado de necesidad y de efecto que generan las mismas en la población.

Respecto a la incidencia laboral del COVID-19, en el momento en que se conocieron los primeros casos en nuestro país, el Poder Ejecutivo, mediante decreto № 093/2020 del 13 de marzo de 2020, dispuso una exhortación a todos los empleadores a implementar el teletrabajo en los domicilios de sus empleados, en la medida en que fuera posible, a lo que, además, el mismo empleador debía proporcionar las herramientas e insumos necesarios para el desarrollo del trabajo domiciliario. En el mismo decreto, se establecieron especificaciones que, hasta el momento, resultan ser las únicas en materia de teletrabajo, ya que no hay en Uruguay una regulación general del tema. Esta exhortación fue cumplida por un gran número de empleados en la medida en que ha sido posible, y nos atrevemos a asegurar de que es una modalidad de trabajo que llegó al Uruguay y al mundo para quedarse.

\subsection{Creación por Ley del Fondo Solidario CORONAVIRUS}

Se trata de una herramienta diseñada por el Gobierno uruguayo creada por la Ley 19.874, mediante la cual se establece el objetivo de cubrir necesidades sanitarias y sociales frente al avance del COVID-19. Esto por cuanto esta crisis económica presenta un escenario que no tiene precedentes, por lo que las herramientas que se proponen tienen el mismo carácter.

EI Fondo CORONAVIRUS se nutre de utilidades provenientes de las empresas públicas y bancos estatales, de recursos obtenidos por préstamos con organismos multilaterales de crédito, de las partidas de prensa del Parlamento y del aporte de los salarios de los funcionarios con sueldo líquido por encima de los $\$ 80.000$-este último se propuso solo durante dos meses excepcionalmente-.

\subsection{Aplicación móvil CORONAVIRUS UY}

Además de las medidas implementadas que fueron desarrolladas anteriormente, el Gobierno uruguayo desarrolló otras herramientas a través del uso de la tecnología, para lograr un mayor alcance sobre todo al sector más joven, ya que, como decíamos párrafos atrás, además de propiciar un escenario adecuado para la delincuencia informática, la tecnología tiene un gran aspecto positivo.

De esta forma, diariamente se publican desde el mes de marzo en las redes sociales relacionadas al Gobierno noticias actualizadas día a día sobre el virus, con la meta de informar el número de contagios, el número de fallecidos, los departamentos 
afectados, etcétera, procurando llegar a todos los ciudadanos para concientizar sobre la propagación del virus.

Más aún, en vías de incorporar el uso de nuevas tecnologías, el gobierno creó una aplicación móvil llamada CORONAVIRUS UY, cuyo fin principal es el seguimiento de casos, y la emisión de alertas en caso de contacto cercano de casos detectados como positivos. Ante la aparición de síntomas en una persona, la aplicación te conecta de inmediato con un prestador de salud para evitar tiempos de espera en la atención. Es importante mencionar que la información recabada por la aplicación se encuentra amparada por las disposiciones de la Ley 18.331, ley de Protección de Datos Personales y acción de Habeas Data, y, sin lugar a dudas, resulta útil.

\footnotetext{
1 Tengan presente que, actualmente, algunas de estas medidas han tenido evolución según el contexto sanitario y económico del ámbito territorial de los centros.

2 "Zonas de alto riesgo": China, Corea del Sur, Irán, Singapur, Japón, Italia, España, Francia, Alemania, Estados Unidos.

${ }^{3}$ Recuperado de: http://www.fiscalia.gub.uy/innovaportal/file/9521/1/formalizacion-covid.pdf
}

\section{Referencias}

Aller, G. (2020). ¿Qué implicaría el delito de desacato durante una cuarentena general?. En diario El País.

Bordes, G. (2016). Breves reflexiones sobre el Art. 1ํ de la reciente ley №19.196 de responsabilidad penal del empleador (Recuperado de: https://publicaciones.fder.edu.uy/index.php/idp/article/view/189).

Cairoli, M. (2000). El derecho penal uruguayo y las nuevas tendencias dogmático penales (tomo I). La ley.

Carrara, F. (1998). Programa de Derecho Criminal. Parte Especial (vol. VI). Editorial Temis.

Código de Procedimiento Penal [CPP]. 7 de julio de 1980 (República Oriental de Uruguay).

Constitución de la República Oriental de Uruguay. 1967 (República Oriental de Uruguay).

Ferreira J., Ramírez G. (2020). El artículo 224 del código penal uruguayo y el reciente proyecto de modificación en medio de una pandemia mundial (Recuperado de: https://laleyuruguay.com/blogs/noticias/el-articulo-224-del-codigo-penaluruguayo-y-el-reciente-proyecto-de-modificacion-en-medio-de-una-pandemiamundial)

Fleitas Villareal, S. (2009). El bien jurídico tutelado en el delito de lavado de activos. Su regulación en la legislación uruguaya (Recuperado de: http://revistaderecho.um.edu.uy/wp-content/uploads/2012/12/Fleitas-VillarrealEl-bien-juridico-tutelado-en-el-delito-de-lavado-de-activos-su-regulacion-en-lalegislacion-uruguaya.pdf).

Roxin, C. (1997). Derecho penal. Parte general. Editorial Civitas.

Silva Sánchez, J. M. (2001). La expansión del Derecho Penal. Aspectos de la política criminal en las sociedades postindustriales. Editorial Civitas. 